\section{D) Check for updates}

Cite this: Polym. Chem., 2020, 11 2381

Received 5th February 2020, Accepted 25th February 2020 DOI: $10.1039 / \mathrm{d} 0$ py00192a rsc.li/polymers

\title{
Mono- and dimeric zinc(II) complexes for PLA production and degradation into methyl lactate - a chemical recycling method $\dagger$
}

\author{
Jack Payne, ${ }^{a}$ Paul McKeown, ${ }^{a}$ Mary F. Mahon, ${ }^{b}$ Emma A. C. Emanuelsson ${ }^{\text {a,c }}$ and \\ Matthew D. Jones (D) *a,b
}

\begin{abstract}
A series of well-defined mono- and dimeric $\mathrm{Zn}(I)$-complexes were prepared and fully characterised by $X$-ray crystallography and NMR spectroscopy. Their application to the ROP of rac-LA to produce biocompatible atactic PLA was demonstrated in both solution and under industrially preferred melt conditions at $180{ }^{\circ} \mathrm{C}$ with a [rac-LA] : [Init] : [BnOH] of $3000: 1: 10$. Exceptional activity was observed in all instances, albeit with generally poor molecular weight control $\left(M_{n}\right)$ and broad dispersities $(\Theta)$, with dimers outperforming their monomeric counterparts. The propensity of all $\mathrm{Zn}(I I)$-complexes to facilitate PLA degradation into methyl lactate (Me-LA) under mild conditions is also demonstrated. $\mathrm{Zn}(\mathbf{2}-\mathbf{3})_{2}$ were identified as the outstanding candidates, achieving full conversion to Me-LA within $8 \mathrm{~h}$ at $80^{\circ} \mathrm{C}$ in THF. Further degradation kinetic analysis revealed $\mathrm{Zn}(2-3)_{2}$ to have $k_{\text {app }}$ values of $0.63 \pm 0.051$ and $0.44 \pm 0.029 \mathrm{~h}^{-1}$ for the rate of consumption of PLA respectively.
\end{abstract}

\section{Introduction}

Petroleum-based polymers (plastics) dominate modern-day society, with annual global production exceeding 300 Mtonnes, of which $c a$. 99\% were derived from petrochemical feedstocks in $2015 .{ }^{1}$ However, it is clear polymer production based on diminishing fossil fuel reserves is unsustainable, with the oil demand for plastics anticipated to rise to $20 \%$ by 2050 from today's value of $6 \% .^{2-5}$ Moreover, plastic pollution, particularly in our oceans, has reached epidemic proportions in recent years, partly due to the intrinsic robustness and durability of plastics, but primarily through the irresponsible handling of plastic waste. ${ }^{6}$ Indeed, it is projected 250 Mtonnes of plastic waste will reside in our oceans by 2025 at current disposal rates. ${ }^{4,7}$ There is therefore a demand for renewable and sustainable alternatives that, ideally, possess facile degradation pathways, a prerequisite to mitigating such concerns. Consequently, renewable polymers have emerged as a promis-

\footnotetext{
${ }^{a}$ Centre for Sustainable and Circular Technologies, University of Bath, Claverton Down, Bath, BA2 7AY, UK

${ }^{b}$ Department of Chemistry, University of Bath, Claverton Down, Bath, BA2 7AY, UK. E-mail:mj205@bath.ac.uk

${ }^{c}$ Department of Chemical Engineering, University of Bath, Claverton Down, Bath, BA2 $7 A Y, U K$

$\dagger$ Electronic supplementary information (ESI) available: Full details of the experimental protocols with selected spectra and raw data. CCDC 1972259-1972264. For ESI and crystallographic data in CIF or other electronic format see DOI: 10.1039/d0py00192a
}

ing alternative to traditional polymers since they can be produced from biomass, which remains a relatively untapped, abundant resource. ${ }^{3}$ Poly(lactic acid) (PLA), a sustainable and biocompatible aliphatic polyester, has emerged as one of the outstanding renewable alternatives within the last 20 years. ${ }^{8}$ PLA has attracted considerable commercial and academic interest, owing to its comparable physical properties with existing synthetic plastics. ${ }^{8,9}$ As such, PLA has found use in singleuse, disposable applications in the packaging sector, but also the biomedical industry, owing to its inherent biocompatibility. ${ }^{3,5,8}$ However, the widespread use of PLA remains limited by a high production cost, which involves the fermentation of lactic acid, prior to subsequent pre-polymerisation steps to produce the cyclic diester monomer, lactide. ${ }^{9}$ Possible solutions include the use of shape selective catalysts and gas-phase reactions, both of which render the monomer preparation less energy and resource intensive..$^{10,11}$ However, despite its green credentials, PLA is still a possible source of plastic pollution since biodegradation occurs exclusively under industrial composting conditions. ${ }^{12}$ Moreover, conventional waste management strategies, including landfill and incineration, align with a linear economic model, a primary contributor to the mounting plastic waste crisis. Indeed, as of 2015, $c a$. 6300 Mtonnes of plastic waste has been produced, and by 2050 it is estimated $c a .12000$ Mtonnes of plastic waste will reside in either landfill or the natural environment. ${ }^{6}$ Thus, there is a clear need to develop alternative targeted waste management technologies to facilitate this transition, namely through 
recycling. ${ }^{4,7}$ Mechanical recycling is one possible solution but is limited by eventual material downgrading due to thermomechanical degradation, resulting in material repurposing to applications that require polymer of lower quality. A promising alternative is chemical recycling, which has the potential to reduce both waste and operational costs through material regeneration, achieved either through the depolymerisation or degradation of PLA. ${ }^{13}$ A number of different methods have been reported in the literature, including hydrolytic and thermal degradation, as well as enzymatic processes. ${ }^{14-23}$ However, the former two rely on high temperature conditions (200-400 ${ }^{\circ} \mathrm{C}$ ), resulting in high operational costs, whilst uncertainty surrounds the scalability of the latter. Alternatively, the transesterification of PLA with alcohols to generate lactate esters has gathered appreciable momentum in recent years (Scheme 1). Low-molecular-weight lactate esters have been cited as green substitutes to traditional hydrocarbon-based solvents, owing to their ease of handling, low toxicity and inherent biodegradability. ${ }^{24}$ As such, lactate esters lend themselves to a variety of different sectors, from polymer and pharmaceuticals manufacturing through to the paints and agricultural chemical industry, to name but a few. ${ }^{25}$ Indeed, it is envisaged that this process will be viable at an industrial scale, both from an economic and environmentally sustainable perspective. ${ }^{26}$ Furthermore, there is the potential to transform lactate esters into platform chemicals, such as lactic acid or lactide, further promoting a circular economy approach. ${ }^{27-29} \mathrm{~A}$ number of different PLA transesterification methods have been reported in the literature. ${ }^{30-44}$ DuPont possess a patent for PLA degradation in the presence of $\mathrm{H}_{2} \mathrm{SO}_{4}$, achieving high conversion (69-87\%) to various lactate esters $(\mathrm{R}=\mathrm{Me}$, Et and ${ }^{n} \mathrm{Bu}$ ) within $2 \mathrm{~h}$ between $150-190{ }^{\circ} \mathrm{C} .{ }^{30}$ Coszach et al. ${ }^{17}$ demonstrated the hydrolysis of PLA to lactic acid, observing enhanced PLA dissolution and polymer separation with lactate esters as the solvent of choice. Hydrolysis proceeded both with or without $\mathrm{NaOH}$, requiring elevated temperatures between 80-180 ${ }^{\circ} \mathrm{C}$ and pressures of up to 10 bar. Catalysts based on rare metals, including iridium and ruthenium, have also been reported for hydrogenation and hydrosilylation processes, but are unattractive options to industry due to a high metal cost. $^{36-38}$ Both Fliedel et $a .^{40}$ and McKeown et $a .^{41}$ have reported systems based on $\mathrm{Zn}$ (II)-complexes, with the latter achieving up to $100 \%$ Me-LA conversion within $1 \mathrm{~h}$ at $90{ }^{\circ} \mathrm{C}$. Interestingly, McKeown et al. ${ }^{42}$ recently demonstrated shifting to an analogous propylenediamine system afforded superior

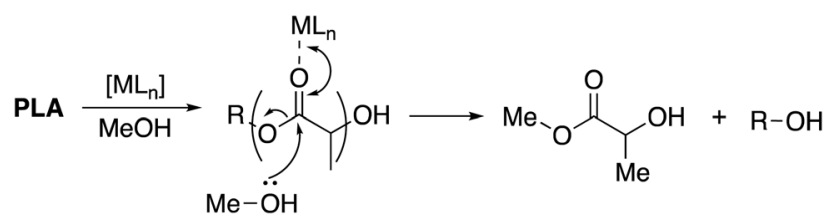

Scheme 1 Metal-mediated degradation mechanism of PLA into methyl lactate via transesterification with $\mathrm{MeOH}$, where $\mathrm{R}$ denotes the growth polymer chain. activity, achieving $81 \%$ conversion within 30 minutes at $50{ }^{\circ} \mathrm{C}$, highlighting the influence of metal-ligand relationships. Petrus et $a{ }^{43}{ }^{43}$ prepared a series of lactate esters from a variety of different alcohols, reporting reaction temperatures as low as $80^{\circ} \mathrm{C}$ in the presence of earth abundant metal-based catalysts, including $\mathrm{Mg}$ (II) and $\mathrm{Ca}$ (II). However, in the absence of a catalyst, reaction temperatures increased to $260{ }^{\circ} \mathrm{C}$, thus highlighting the benefits of metal-mediated degradation, particularly from an economic and environmental standpoint. However, despite the need for simple, controlled metal-mediated degradation pathways, literature examples remain limited. There is therefore a clear opportunity to develop robust, industrially viable catalysts based on both earth abundant metals and scalable ligand systems. Herein, we report the synthesis of a series of mono- and dimeric $\mathrm{Zn}(\mathrm{II})-$ Schiff-base complexes, and their application to the ROP of rac-lactide in both solution and under industrially preferred melt conditions is demonstrated. The metal-mediated degradation of PLA into Me-LA under mild conditions is also reported, in conjunction with a reaction kinetic study.

\section{Results and discussion}

\section{Synthesis}

A range of simple Schiff-base ligands were prepared via an imine condensation reaction (Scheme 2) and characterised by ${ }^{1} \mathrm{H}$ NMR spectroscopy and mass spectrometry. ${ }^{1} \mathrm{H}$ NMR singlets at $c a . \delta=8$ and $14 \mathrm{ppm}$ were assigned to characteristic $\mathrm{HC}=\mathrm{N}$ and $\mathrm{O}-\mathrm{H}$ resonances respectively. Mono- and dimeric complexes of $\mathrm{Zn}$ (II) were then prepared in anhydrous toluene and purified by hexane recrystallisation or via washing (Scheme 2). To alleviate safety concerns associated with the pyrophoric alkyl precursor employed $\left(\mathrm{ZnEt}_{2}\right)$, the synthesis of $\mathrm{Zn}(\mathbf{1})_{2}$ was attempted from $\mathrm{Zn}(\mathrm{OAc})_{2} \cdot 2 \mathrm{H}_{2} \mathrm{O}$ in EtOH under reflux conditions but proved unsuccessful. In the solid state, $\mathrm{Zn}(\mathbf{1}-\mathbf{3})_{2}$ and $\mathrm{Zn}_{2}(\mathbf{1}, \mathbf{3})_{2}(\mathrm{Et})_{2}$ exhibited a distorted tetrahedral geometry around the metal centre, consistent with a $\tau_{4}$ value close to 1

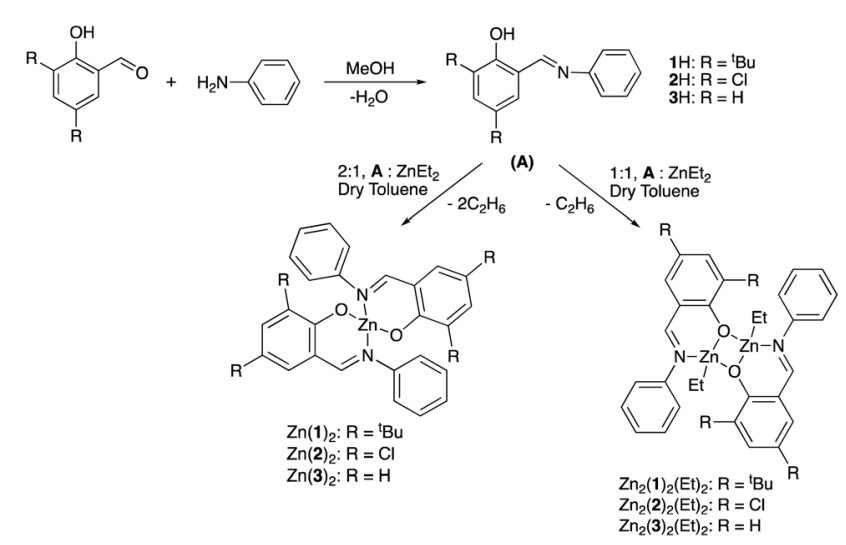

Scheme 2 Schiff-base ligand preparation and their complexation to $\mathrm{Zn}(\mathrm{II})$ to afford a series of mono-, $\mathrm{Zn}(1-3)_{2}$, and analogous dimeric, $\mathrm{Zn}_{2}(1-3)_{2}(\mathrm{Et})_{2}$, complexes. 
Table 1 Selected bond angles for $\mathrm{Zn}(1-3)_{2}$ and $\mathrm{Zn}_{2}(1-3)_{2}(\mathrm{Et})_{2}$ with calculated $\tau_{4}$ values. Ideal tetrahedral geometry corresponds to $\tau_{4}=1$

\begin{tabular}{llll}
\hline Init. & Bond & Bond angle/o & $\tau_{4}$ \\
\hline $\mathrm{Zn}(1)_{2}$ & $\mathrm{O}(1)-\mathrm{Zn}(1)-\mathrm{N}(2), \mathrm{O}(2)-\mathrm{Zn}(1)-\mathrm{N}(1)$ & $115.26(8), 155.48(8)$ & $113.54(5), 126.19(5)$ \\
$\mathrm{Zn}(2)_{2}$ & $\mathrm{O}(2)-\mathrm{Zn}(1)-\mathrm{N}(1), \mathrm{N}(1)-\mathrm{Zn}(1)-\mathrm{N}(2)$ & $119.02(6), 121.68(6)$ \\
$\mathrm{Zn}(3)_{2}$ & $\mathrm{O}(2)-\mathrm{Zn}(1)-\mathrm{N}(1), \mathrm{O}(1)-\mathrm{Zn}(1)-\mathrm{N}(2)$ & $124.10(15), 132.40(16)$ \\
$\mathrm{Zn}_{2}(\mathbf{1})_{2}(\mathrm{Et})_{2}$ & $\mathrm{C}(1)-\mathrm{Zn}(1)-\mathrm{O}(1), \mathrm{C}(1)-\mathrm{Zn}(1)-\mathrm{N}(2)$ & $124.86(10), 129.61(10)$ & 0.85 \\
$\mathrm{Zn}_{2}(\mathbf{2})_{2}(\mathrm{Et})_{2}$ & $\mathrm{C}(1)-\mathrm{Zn}(1)-\mathrm{N}(1), \mathrm{C}(1)-\mathrm{Zn}(1)-\mathrm{O}(1)$ & $125.13(8), 134.65(8)$ & 0.73 \\
$\mathrm{Zn}_{2}(\mathbf{3})_{2}(\mathrm{Et})_{2}$ & $\mathrm{C}(1)-\mathrm{Zn}(1)-\mathrm{O}(1), \mathrm{C}(1)-\mathrm{Zn}(1)-\mathrm{N}(1)$ & & 0.75 \\
& &
\end{tabular}

(Table 1). XRD analysis revealed $\mathrm{Zn}_{2}(\mathbf{1}-\mathbf{3})_{2}(\mathrm{Et})_{2}$ to adopt a phenoxy-bridged dimeric structure. In all instances, the $\mathrm{Zn}-\mathrm{O}$ bond lengths increased between mono- and dimeric analogues, consistent with the observed shift from a $2 \mathrm{c}-2 \mathrm{e}^{-}$to $3 \mathrm{c}-$ $2 \mathrm{e}^{-}$bonding system $\left\{\mathrm{Zn}(2)_{2}: \mathrm{Zn}(1)-\mathrm{O}(1)=1.9297(11) \AA\right.$, $\mathrm{Zn}_{2}(2)_{2}(\mathrm{Et})_{2}: \mathrm{Zn}(1)-\mathrm{O}(1)=2.0293(17) \AA$ A $\}$. A $\mathrm{Zn}(1)-\mathrm{N}(2)$ bond length of $c a .2 \AA$ confirmed the retention of the imine functionality on coordination to $\mathrm{Zn}$ (II) for all complexes (Fig. 1), consistent with previously reported $\mathrm{Zn}$ (II)-complexes. ${ }^{45}$ This was reaffirmed by ${ }^{1} \mathrm{H}$ NMR spectroscopic analysis, which exhibited a characteristic singlet peak at ca. 8 ppm corresponding to a $\mathrm{HC}=\mathrm{N}$ resonance. Additionally, the absence of a singlet resonance around $14 \mathrm{ppm}$, present in the isolated ligand, confirmed the loss of $\mathrm{O}-\mathrm{H}$ functionality on coordination to the $\mathrm{Zn}$ (II) centre (Fig. 1). In all cases, ${ }^{1} \mathrm{H}$ NMR spectra suggested identical ligand coordination environments for each
$\mathrm{Zn}$ (II)-complex in solution, with the exception of $\mathrm{Zn}_{2}(\mathbf{1})_{2}(\mathrm{Et})_{2}$. Four singlet peaks corresponding to ${ }^{\mathrm{t}} \mathrm{Bu}$ resonances were observed for $\mathrm{Zn}_{2}(\mathbf{1})_{2}(\mathrm{Et})_{2}$, suggesting multiple species present in solution. Diffusional ordered spectroscopy (DOSY) NMR analysis indicated the presence of two distinct species in solution, as a consequence of the Schlenk type equilibrium, corresponding to $\mathrm{Zn}(\mathbf{1})_{2}$ and $\mathrm{Zn}(\mathbf{1})$ Et with diffusion constants $(D)$ of $0.6 \times 10^{-9}$ and $0.8 \times 10^{-9} \mathrm{~m}^{2} \mathrm{~s}^{-1}$ respectively (see ESI $\dagger$ ). $\mathrm{Zn}(\mathbf{1})$ Et, instead of $\mathrm{Zn}_{2}(\mathbf{1})_{2} \mathrm{Et}_{2}$, is proposed due to the large $D$ observed.

A comparison between the ${ }^{1} \mathrm{H}$ NMR spectra of $\mathrm{Zn}_{2}(2-3){ }_{2} \mathrm{Et}_{2}$ with their respective monomeric counterparts indicates no presence of the homoleptic species, and thus are not susceptible to the Schlenk type equilibrium noted for $\mathrm{Zn}_{2}(\mathbf{1})_{2}(\mathrm{Et})_{2}$. It is proposed $\mathrm{Zn}(\mathbf{1}) \mathrm{Et}$ is stabilised by the steric bulk of $\mathbf{1 H}$. For $\mathrm{Zn}_{2}(1-3)_{2}(\mathrm{Et})_{2}$, resonances in the region of $c a . \delta 0.5-1.5 \mathrm{ppm}$
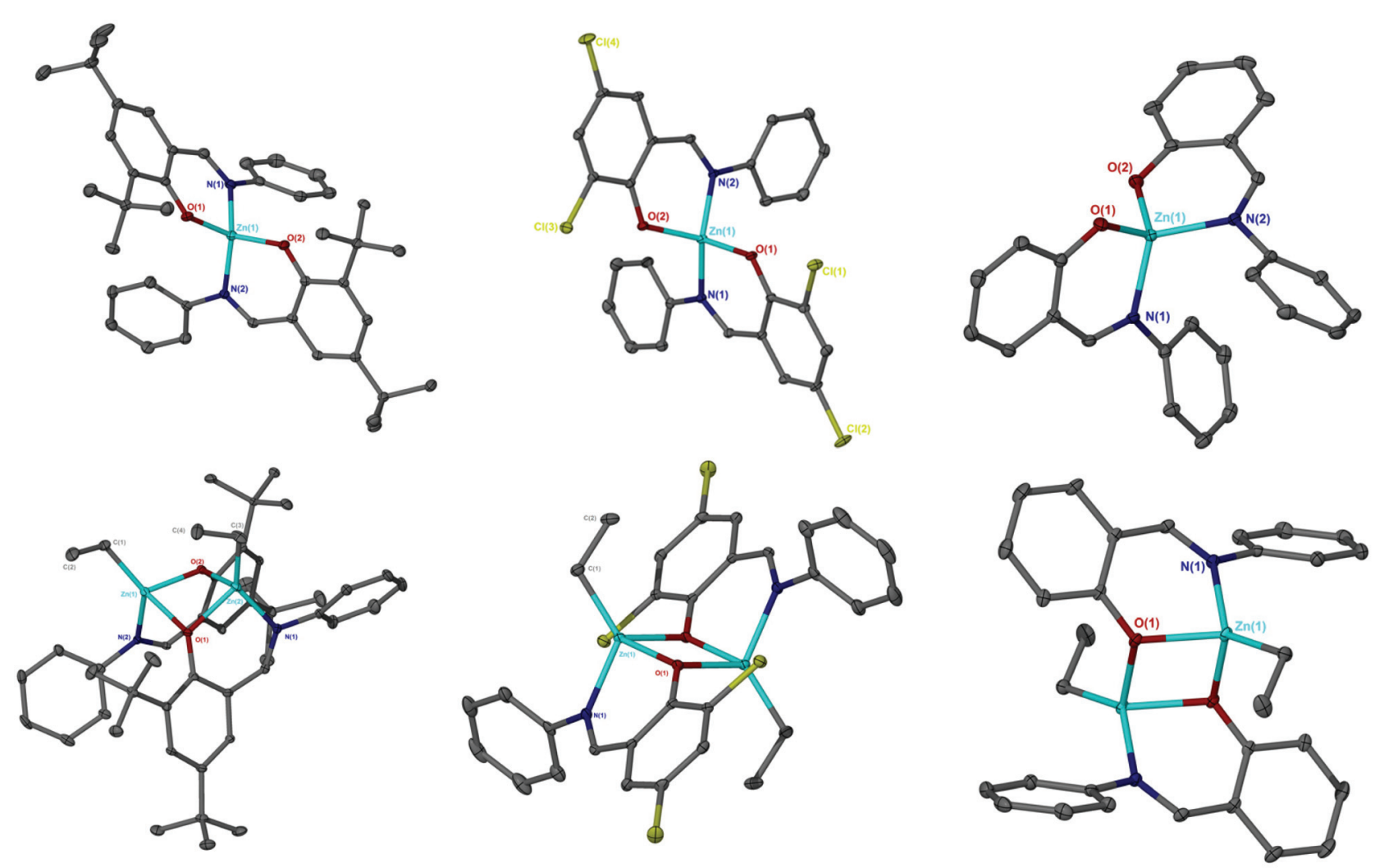

Fig. 1 Solid-state structures of $\mathrm{Zn}(1-3)_{2}$ (top left to right) and $\mathrm{Zn}_{2}(1-3)_{2}(E \mathrm{Et})_{2}$ (bottom left to right). Ellipsoids shown at $30 \%$ probability, with all hydrogen atoms, and one toluene molecule for $\mathrm{Zn}(1-2)_{2}$, omitted for clarity. 
confirmed coordination of Et- to $\mathrm{Zn}$ (II) in solution, consistent with XRD analysis. Interestingly, trans-Et coordination was observed in $\mathrm{Zn}_{2}(2-3)_{2}(\mathrm{Et})_{2}$ compared to cis-Et in $\mathrm{Zn}_{2}(\mathbf{1})_{2}(\mathrm{Et})_{2}$. This is likely a consequence of reduced steric demand in $\mathrm{Zn}_{2}(\mathbf{2 - 3})_{2}(\mathrm{Et})_{2}$ compared to $\mathrm{Zn}_{2}(\mathbf{1})_{2}(\mathrm{Et})_{2} \cdot{ }^{13} \mathrm{C}\left\{{ }^{1} \mathrm{H}\right\} \mathrm{NMR}$ analysis was consistent with XRD and ${ }^{1} \mathrm{H}$ NMR data, although poor peak resolution was observed for both $\mathrm{Zn}(2)_{2}$ and $\mathrm{Zn}_{2}(2)_{2}(\mathrm{Et})_{2}$, indicative of fluxionality on the ${ }^{13} \mathrm{C}\left\{{ }^{1} \mathrm{H}\right\}$ NMR timescale. All Zn (II)-complexes were generally in good agreement with elemental analysis (EA) data obtained. The scalability of these complexes was also demonstrated, producing $14.6 \mathrm{~g}$ of $\mathrm{Zn}(2)_{2}$ in exceptional yield (87\%).

\section{Polymerisation}

All $\mathrm{Zn}$ (II)-complexes were trialled for the polymerisation of raclactide ( $r a c$-LA) under both industrially preferred conditions in the absence of solvent at elevated temperatures (Tables 2 and 3) and in solution (Table 4). Catalysts that operate under industrially viable conditions are desirable since they remove the need for solvents, which are typically a significant source of waste. ${ }^{45-49}$ The lactide monomer, rac-LA, was recrystallised from toluene once prior to use, and benzyl alcohol was employed as a co-initiator. Conversion was determined via analysis of the methine region ( $c a . \delta 4.9-5.2 \mathrm{ppm}$ ) by means of ${ }^{1} \mathrm{H}$ NMR spectroscopy. All initiators demonstrated rapid polymerisation at $130{ }^{\circ} \mathrm{C}$, achieving high conversion within minutes $\{[r a c-\mathrm{LA}]:[$ Init $]:[\mathrm{BnOH}]=300: 1: 1\}$ (Table 2). The reduction in activity of $\mathrm{Zn}(\mathbf{1})_{2}$ compared to $\mathrm{Zn}(2-3)_{2}$ could likely be attributed to reduced steric bulk of the substituted phenoxy-fragment. In all instances, $\mathrm{Zn}_{2}(\mathbf{1}-\mathbf{3})_{2}(\mathrm{Et})_{2}$ exhibited superior activity compared to their respective monomeric counterparts. It is proposed $\mathrm{Zn}(\mathbf{1}-\mathbf{3})_{2}$ operate via an activated

Table 2 Polymerisation of rac-LA at $130^{\circ} \mathrm{C}$ using $\mathrm{Zn}($ II)-complexes

\begin{tabular}{|c|c|c|c|c|c|c|c|}
\hline Init. & {$[r a c-\mathrm{LA}]:[\mathrm{I}]:[\mathrm{BnOH}]$} & Time/min & Conv. ${ }^{a} / \%$ & $M_{\mathrm{n} / \text { theo }^{b}}{ }^{b}$ & $M_{\mathrm{n}}{ }^{c}$ & $\bigoplus^{c}$ & $\mathrm{P}_{\mathrm{r}}^{d}$ \\
\hline \multirow[t]{2}{*}{$\operatorname{Zn}(\mathbf{1})_{2}$} & $300: 1: 1$ & 9 & 69 & 29900 & 16650 & 1.86 & 0.56 \\
\hline & $300: 1: 6$ & 10 & 90 & 6600 & 13000 & 1.46 & 0.54 \\
\hline $\mathrm{Zn}(2)_{2}$ & $300: 1: 1$ & 2 & 78 & 33800 & 26600 & 1.75 & 0.54 \\
\hline $\mathrm{Zn}(3)_{2}$ & $300: 1: 1$ & 2 & 88 & 38100 & 43700 & 1.98 & 0.54 \\
\hline $\mathrm{Zn}_{2}(\mathbf{1})_{2} \mathrm{Et}_{2}$ & $300: 1: 1$ & 2 & 88 & 38100 & 25350 & 1.99 & 0.55 \\
\hline $\mathrm{Zn}_{2}(2)_{2} \mathrm{Et}_{2}$ & $300: 1: 1$ & $<1$ & 72 & 31200 & 17000 & 1.67 & 0.54 \\
\hline $\mathrm{Zn}_{2}(3)_{2} \mathrm{Et}_{2}$ & $300: 1: 1$ & 2 & 96 & 41600 & 46600 & 2.20 & 0.53 \\
\hline
\end{tabular}

Conditions: rac-LA, solvent free $\left(130^{\circ} \mathrm{C}\right) .{ }^{a}$ Determined via ${ }^{1} \mathrm{H}$ NMR spectroscopy. ${ }^{b}$ Theoretical average number molecular weight $\left(M_{\mathrm{n}}\right)$ dependent on conversion and co-initiator added $\left.\left\{\left(M_{\mathrm{r}, \mathrm{LA}} \times 3 \times \%_{\mathrm{conv}}\right)+M_{\mathrm{n}, \mathrm{BnOH}}\right)\right\} .{ }^{c}$ Determined via GPC analysis (in THF). ${ }^{d}$ Determined via homonuclear decoupled NMR spectroscopy. Note $\{[\mathrm{I}]:[\mathrm{BnOH}]=1: 1\}$ corresponds to 1 equivalent of $\mathrm{BnOH}$ per $\mathrm{Zn}$ centre.

Table 3 Polymerisation of rac-LA at $180^{\circ} \mathrm{C}$ using $\mathrm{Zn}(\mathrm{II})$-complexes

\begin{tabular}{|c|c|c|c|c|c|c|c|}
\hline Init. & {$[r a c-\mathrm{LA}]:[\mathrm{I}]:[\mathrm{BnOH}]$} & Time/min & Conv. ${ }^{a} / \%$ & $M_{\mathrm{n} / \text { theo }}{ }^{b}$ & $\mathbf{M}_{\mathrm{n}}{ }^{c}$ & $\bigoplus^{c}$ & $P_{\mathrm{r}}^{d}$ \\
\hline $\operatorname{Zn}(\mathbf{1})_{2}$ & $3000: 1: 10$ & 18 & 47 & 20400 & 63450 & 1.96 & 0.58 \\
\hline $\mathrm{Zn}(2)_{2}$ & $3000: 1: 10$ & $<1$ & 55 & 23850 & 124400 & 1.95 & 0.58 \\
\hline $\mathrm{Zn}(3)_{2}$ & $3000: 1: 10$ & 10 & 72 & 31200 & 116800 & 2.04 & 0.58 \\
\hline $\mathrm{Zn}_{2}(\mathbf{1})_{2} \mathrm{Et}_{2}$ & $3000: 1: 10$ & $<1$ & 92 & 39850 & 61200 & 2.04 & 0.58 \\
\hline $\mathrm{Zn}_{2}(2)_{2} \mathrm{Et}_{2}$ & $3000: 1: 10$ & $<1$ & 94 & 40700 & 54550 & 1.91 & 0.56 \\
\hline $\mathrm{Zn}_{2}(3)_{2} \mathrm{Et}_{2}$ & $3000: 1: 10$ & $<1$ & 88 & 38100 & 40000 & 1.83 & 0.58 \\
\hline
\end{tabular}

Conditions: $r a c$-LA, solvent free $\left(180^{\circ} \mathrm{C}\right) .{ }^{a}$ Determined via ${ }^{1} \mathrm{H}$ NMR spectroscopy. ${ }^{b}$ Theoretical average number molecular weight $\left(M_{\mathrm{n}}\right)$ dependent on conversion and co-initiator added $\left.\left\{\left(M_{\mathrm{r}, \mathrm{LA}} \times 3 \times \%_{\mathrm{conv}}\right)+M_{\mathrm{n}, \mathrm{BnOH}}\right)\right\} .{ }^{c}$ Determined via GPC analysis (in THF). ${ }^{d}$ Determined via homonuclear decoupled NMR spectroscopy. Note $\{[\mathrm{I}]:[\mathrm{BnOH}]=1: 1\}$ corresponds to 1 equivalent of $\mathrm{BnOH}$ per $\mathrm{Zn}$ centre.

Table 4 Polymerisation of rac-LA at $80^{\circ} \mathrm{C}$ using $\mathrm{Zn}(॥)$-complexes

\begin{tabular}{|c|c|c|c|c|c|c|c|}
\hline Init. & {$[r a c-\mathrm{LA}]:[\mathrm{I}]:[\mathrm{BnOH}]$} & Time/h & Conv. $^{a} / \%$ & $M_{\mathrm{n} / \text { theo }}{ }^{b}$ & $M_{\mathrm{n}}{ }^{c}$ & $\bigoplus^{c}$ & $P_{\mathrm{r}}^{d}$ \\
\hline $\mathrm{Zn}(\mathbf{1})_{2}$ & $100: 1: 1$ & 2 & 70 & 10200 & 8800 & 1.27 & 0.46 \\
\hline $\mathrm{Zn}(2)_{2}$ & $100: 1: 1$ & 0.50 & 95 & 13800 & 12600 & 1.83 & 0.51 \\
\hline $\mathrm{Zn}(3)_{2}$ & $100: 1: 1$ & 0.50 & 96 & 13950 & 16200 & 1.73 & 0.50 \\
\hline $\mathrm{Zn} 2(\mathbf{1})_{2} \mathrm{Et}_{2}$ & $100: 1: 1$ & 0.17 & 92 & 13350 & 12600 & 1.21 & 0.53 \\
\hline \multirow[t]{2}{*}{$\mathrm{Zn} 2(2)_{2} \mathrm{Et}_{2}$} & $100: 1: 1$ & 0.17 & 96 & 13900 & 12650 & 1.42 & 0.55 \\
\hline & $100: 1: 1$ & $30^{e}$ & 83 & 12050 & 11900 & 1.22 & 0.59 \\
\hline \multirow{2}{*}{$\mathrm{Zn} 2(3)_{2} \mathrm{Et}_{2}$} & $100: 1: 1$ & 0.17 & 96 & 13900 & 12000 & 1.24 & 0.47 \\
\hline & $100: 1: 1$ & $24^{e}$ & 99 & 14350 & 10850 & 1.44 & 0.58 \\
\hline
\end{tabular}

Conditions: rac-LA, solvent (toluene, $\left.80{ }^{\circ} \mathrm{C}\right) .{ }^{a}$ Determined via ${ }^{1} \mathrm{H}$ NMR spectroscopy. ${ }^{b}$ Theoretical average number molecular weight $\left(M_{\mathrm{n}}\right)$ dependent on conversion and co-initiator added $\left.\left\{\left(M_{\mathrm{r}, \mathrm{LA}} \times \%_{\text {conv }}\right)+M_{\mathrm{n}, \mathrm{BnOH}}\right)\right\} .{ }^{c}$ Determined via GPC analysis (in THF). ${ }^{d}$ Determined via homonuclear decoupled NMR spectroscopy. ${ }^{e}$ RT. Note $\{[\mathrm{I}]:[\mathrm{BnOH}]=1: 1\}$ corresponds to 1 equivalent of BnOH per $\mathrm{Zn}$ centre. 
monomer mechanism, whilst $\mathrm{Zn}_{2}(\mathbf{1}-\mathbf{3})_{2}(\mathrm{Et})_{2}$ operate via a coordination- insertion mechanism once the labile Et- group is displaced by $-\mathrm{OBn}$. To investigate this the stability of $\mathrm{Zn}(\mathbf{1})_{2}$ and $\mathrm{Zn}_{2}(3)_{2}(\mathrm{Et})_{2}$ in $\mathrm{BnOH}$ was studied. ${ }^{1} \mathrm{H}$ NMR analysis revealed the former to be stable, whilst the latter converted to the corresponding $\mathrm{BnO}-$ analogue via elimination of the terminal -Et to afford dissolved ethane (see ESI $\dagger$ ), consistent with the emergence of a single $\mathrm{CH}_{3}$ resonance at $c a . \delta=0.80 \mathrm{ppm}$, as expected. These results are compatible with the respective suggested mechanisms. $\mathrm{Zn}(3)_{2}$ and $\mathrm{Zn}_{2}(3)_{2}(\mathrm{Et})_{2}$ achieved the highest conversions of $88 \%$ and $96 \%$ respectively within 2 minutes, suggesting reduced sterics dominates electron withdrawing inductive effects in both subseries. All initiators offered moderate number average molecular weight $\left(M_{\mathrm{n}}\right)$ control, with broad dispersities $(D=1.67-2.20)$ observed under these conditions. Reduced $M_{\mathrm{n}}$ control may also be due to rapid polymerisation ( $<1 \mathrm{~min}$ ) inhibiting homogeneity, thus preventing optimal initiation. $\mathrm{Zn}(\mathbf{1})_{2}$ was repeated at $\{[\mathrm{rac}-$ LA $]:[$ Init $]:[\mathrm{BnOH}]=300: 1: 6\}$ to afford PLA of sufficiently low $M_{\mathrm{n}}$ weight for end group characterisation. MALDI-ToF analysis confirmed the polymer (Table 2, entry 2) to be $-\mathrm{OBn}$ and $-\mathrm{H}$ end-capped with multiple series present suggesting poor polymerisation control, consistent with GPC data. For all Zn(II)initiators, polymerisation of rac-LA afforded atactic PLA $\left(P_{\mathrm{r}} \approx\right.$ $0.5)$. Whilst maintaining a constant $r a c$-LA : co-initiator ratio at reduced catalyst loading $\{[r a c-L A]:[\operatorname{Init}]:[\mathrm{BnOH}]=3000: 1: 10\}$ (Table 3), increasing the temperature to $180{ }^{\circ} \mathrm{C}$ resulted in a shift to very slight heterotactic PLA $\left(P_{\mathrm{r}}=0.58\right)$. Generally, accelerated polymerisation $(<1 \mathrm{~min})$ was observed at higher temperatures, with the exception of $\mathrm{Zn}(\mathbf{1}, \mathbf{3})_{2} \cdot \mathrm{Zn}_{2}(\mathbf{1}-\mathbf{3})_{2}(\mathrm{Et})_{2}$ exhibited superior activity compared to their monomeric analogues, consistent with observations at $130^{\circ} \mathrm{C}$. At $3000: 1: 10$, moderate $M_{\mathrm{n}}$ control and broad dispersities $(D=1.83-2.04)$ were observed, consistent with observations at $130{ }^{\circ} \mathrm{C}$. However, GPC analysis revealed both $\mathrm{Zn}(2-3)_{2}$ produced PLA of significantly higher $M_{\mathrm{n}}$ than predicted. Superior $M_{\mathrm{n}}$ control was achieved at lower polymerisation temperatures $\left(80^{\circ} \mathrm{C}\right)$ in solution $\{[$ rac-LA $]:[$ Init $]:[\mathrm{BnOH}]=100: 1: 1\}$ (Table 4), producing atactic PLA $\left(\mathrm{P}_{\mathrm{r}} \approx 0.5\right)$ with broad dispersities $(\nexists=1.21-1.83)$. All Zn(II)-initiators achieved high conversion $(\geq 92 \%)$ within 10 to 30 minutes, with the exception of $\operatorname{Zn}(\mathbf{1})_{2}$, which achieved $70 \%$ conversion after $2 \mathrm{~h}$, consistent with observations at 130 and $180^{\circ} \mathrm{C}$. MALDI-ToF analysis revealed the polymer (Table 4, entry 1) to be BnO- and - $\mathrm{H}$ end-capped, with molecular weight consistent with GPC and observations in the melt (see ESI $\dagger$ ). A second series of lower intensity was observed corresponding to transesterified polymer, an initial indication of the catalysts propensity to facilitate PLA degradation.

Interestingly, all dimers exhibited exceptional $M_{\mathrm{n}}$ control, which is considerably poorer under extended periods of polymerisation $(D=1.63-2.21$ after $2 \mathrm{~h})$, presumably due to detrimental transesterification. It was envisaged the trans-Et-configuration in $\mathrm{Zn}_{2}(2-3)_{2}(\mathrm{Et})_{2}$ would facilitate coordination of initiated polymer chains above and below the plane of the $\mathrm{Zn}(\mathrm{II})-\mathrm{O}-\mathrm{Zn}$ (II) framework, resulting in superior monomer selectivity. Therefore, the solution polymerisations were repeated at RT. Both $\mathrm{Zn}_{2}(2-3)_{2}(\mathrm{Et})_{2}$ exhibited a shift to very slight heterotactic PLA $\left(P_{\mathrm{r}}=0.58-0.59\right)$ and narrower dispersities $(\theta=1.22-1.44)$ compared to $80{ }^{\circ} \mathrm{C}$, suggesting enhanced control at the expense of high catalyst activity, consistent with the literature. ${ }^{45} \mathrm{Zn}_{2}(2)_{2}(\mathrm{Et})_{2}$ displayed exceptional $M_{\mathrm{n}}$ control under these conditions $\left(M_{\mathrm{n}},=11900 ; M_{\mathrm{n}, \text { theo }}=12050\right)$. Reactivity trends were consistent with those observed in the melt at $130{ }^{\circ} \mathrm{C}$, with $\mathrm{Zn}_{2}(3)_{2}(\mathrm{Et})_{2}$ achieving $99 \%$ conversion within $24 \mathrm{~h}$. Under solution conditions, it is tentatively suggested the original dimeric framework of $\mathrm{Zn}_{2}(2-3)_{2} \mathrm{Et}_{2}$, is retained, although there is existing literature precedent for benzoxy bridged dinuclear Zn(II)-initiators. ${ }^{50-53}$ In light of DOSY NMR analysis, presence of the Schlenk type equilibrium for $\mathrm{Zn}_{2}(\mathbf{1})_{2} \mathrm{Et}_{2}$ inhibits the rationale for the proposed species. In summary, all $\mathrm{Zn}$ (II)-initiators exhibited high catalyst activity in the polymerisation of rac-LA, consistent with previous examples in the literature. ${ }^{41,42,45,46,50-63}$

\section{Polymerisation kinetics}

Generally, $\mathrm{Zn}_{2}(\mathbf{1}-3)_{2} \mathrm{Et}_{2}$ outperformed their monomeric counterparts under both melt and solution conditions. A mono- $v s$. dimeric system kinetic study was envisaged but not possible due to the extremely high activity of the latter. To this end, $\mathrm{Zn}(\mathbf{1})_{2}$ and $\mathrm{Zn}(2)_{2}$ were chosen to better understand the impact of steric and electronic effects on polymerisation activity in solution (Fig. 2 and 3). The consumption of rac-LA was shown to adopt first-order kinetics as demonstrated by the linear relationship of $\ln \left([\mathrm{LA}]_{0} /[\mathrm{LA}]_{t}\right)$ against time (Fig. 2). $\mathrm{Zn}(\mathbf{1})_{2}$ and $\mathrm{Zn}(2)_{2}$ exhibited apparent rate constants $\left(k_{\mathrm{app}}\right)$ of 0.0068 and $0.081 \mathrm{~min}^{-1}$ respectively, indicating reduced sterics, coupled with a more electron withdrawing ligand, affords enhanced polymerisation activity with statistical significance. GPC analysis of the retained aliquots for $\mathrm{Zn}(\mathbf{1})_{2}$ confirmed the polymerisation to be well controlled and living, demonstrated by a linear increase in $M_{\mathrm{n}}$ with conversion, whilst retaining a narrow $D$ range (Fig. 3).

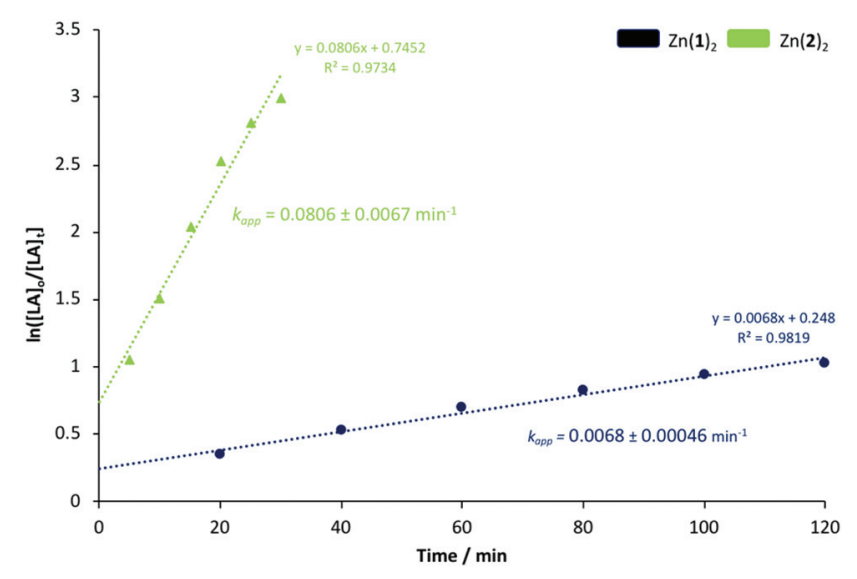

Fig. 2 First-order logarithmic plot for the polymerisation of rac-LA at $80{ }^{\circ} \mathrm{C}$ in toluene $\{[\mathrm{rac}-\mathrm{LA}]:[\mathrm{l}]:[\mathrm{BnOH}]=100: 1: 1\}$ using $\mathrm{Zn}(1)_{2}$ and $\mathrm{Zn}$ (2) 2 . Note $[L A]_{0}=0.69 \mathrm{~mol} \mathrm{dm}^{-3}$. 


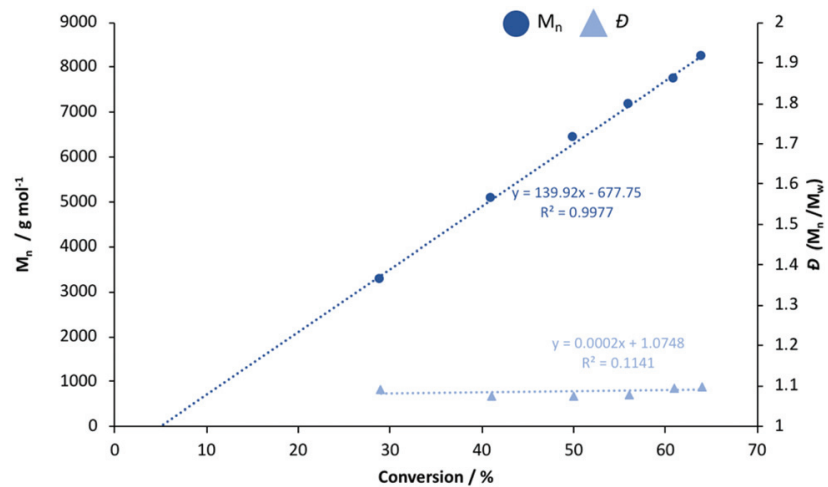

Fig. $3 M_{\mathrm{n}}$ and $\bigoplus$ against conversion for the solution polymerisation of rac-LA in toluene at $80^{\circ} \mathrm{C}$ using $\mathrm{Zn}(1)_{2}$

\section{Degradation}

All Zn(II)-complexes were investigated in the metal-mediated degradation of PLA into methyl lactate (Me-LA) in solution between $50-80{ }^{\circ} \mathrm{C}$ (Table 5). In addition to Me-LA being a green alternative to traditional petrochemical based solvents, it can also be directly converted to lactide and is therefore a potentially valuable chemical to the PLA supply chain. ${ }^{24,25,64}$ Commercially available polymer $\left(0.25 \mathrm{~g}\right.$, Vegware ${ }^{\mathrm{TM}}$, PLA cup, $M_{\mathrm{n}}=45510 \mathrm{~g} \mathrm{~mol}^{-1}$ ) and catalyst were dissolved in THF under $\mathrm{Ar}$, with heat and stirring assisting dissolution. $\mathrm{MeOH}$ was then added, and the conversion to Me-LA was determined via ${ }^{1} \mathrm{H}$ NMR analysis of the methine region (ca. $\delta 4.2-5.2 \mathrm{ppm}$ ). We have previously demonstrated the production of Me-LA proceeds via a two-step process through the intermediate formation of chain-end groups (see ESI $\dagger$ ). ${ }^{41}$ As such, the methine groups can be categorised as internal (int), chain end (CE) and those corresponding directly to the alkyl lactate (Me-LA), as denoted in Table 5. In general, reasonably good catalyst activity was observed under milder reaction conditions compared to previously reported recycling systems. ${ }^{14,15,18,33,37,38,43,65-69}$ In all instances, an increase in temperature coincided with

Table 5 Degradation of PLA into Me-LA using Zn(II)-complexes ${ }^{a, b}$

\begin{tabular}{llllll}
\hline Init. & Time $/ \mathrm{h}$ & $T /{ }^{\circ} \mathrm{C}$ & $Y_{\mathrm{Me}-\mathrm{LA}} / \%$ & $Y_{\mathrm{CE}} / \%$ & $X_{\text {int }} / \%$ \\
\hline $\mathrm{Zn}(\mathbf{1})_{2}$ & 18 & 50 & 41 & 22 & 37 \\
& 8 & 80 & 54 & 18 & 28 \\
$\mathrm{Zn}(2)_{2}$ & 18 & 50 & 88 & 6 & 6 \\
& 8 & 80 & 100 & 0 & 0 \\
$\mathrm{Zn}(3)_{2}$ & 18 & 50 & 77 & 13 & 10 \\
& 8 & 80 & 100 & 0 & 0 \\
$\mathrm{Zn}_{2}(\mathbf{1})_{2}(\mathrm{Et})_{2}$ & 18 & 50 & 57 & 17 & 26 \\
$\mathrm{Zn}_{2}(2)_{2}(\mathrm{Et})_{2}$ & 8 & 80 & 81 & 11 & 8 \\
$\mathrm{Zn}_{2}(3)_{2}(\mathrm{Et})_{2}$ & 18 & 50 & 71 & 13 & 16 \\
& 8 & 80 & 88 & 7 & 5 \\
& 18 & 50 & 52 & 21 & 27 \\
& 80 & 100 & 0 & 0
\end{tabular}

${ }^{a}$ Reaction conditions: $0.25 \mathrm{~g}$ of PLA, $\mathrm{V}_{\mathrm{THF}}: \mathrm{V}_{\mathrm{MeOH}}=4: 1,\left[\mathrm{Zn}(1-3)_{2} /\right.$ $\left.\mathrm{Zn}_{2}(1-3)_{2}(\mathrm{Et})_{2}\right]=8 \mathrm{wt} \%$ cat. loading, $n_{\mathrm{MeOH}}: \mathrm{n}_{\text {ester }}=7: 1 .{ }^{b} \mathrm{Me}-\mathrm{LA}$ and oligomer yield ( $Y_{\mathrm{Me}-\mathrm{LA}}$ and $Y_{\mathrm{CE}}$ respectively) determined by ${ }^{1} \mathrm{H}$ NMR upon solvent (THF) removal. higher Me-LA yield ( $\left.Y_{\text {Me-LA }}\right)$ and shorter reaction times, consistent with the literature. ${ }^{35,41,43} \mathrm{Zn}(2)_{2}$ exhibited superior activity compared to $\mathrm{Zn}(\mathbf{1}, 3)_{2}$ at $50{ }^{\circ} \mathrm{C}$, suggesting inductive effects dominate, whilst $\mathrm{Zn}(\mathbf{1})_{2}$ exhibited the lowest degradation activity, both consistent with polymerisation results (Table 3). As noted previously, a shift to the corresponding dimeric analogue, $\mathrm{Zn}_{2}(\mathbf{1})_{2}(\mathrm{Et})_{2}$, coincided with superior activity at both 50 and $80{ }^{\circ} \mathrm{C}$, with the exception of $\mathrm{Zn}(2-3)_{2}$. This was likely due to reduced sterics in the latter two rendering the dimeric counterparts more susceptible to decomposition at $50{ }^{\circ} \mathrm{C}$, resulting in deactivation. It is suggested this effect was remediated by an increase in rate of reaction at $80^{\circ} \mathrm{C}$. Indeed, both $\mathrm{Zn}(2-3)_{2}$ and $\mathrm{Zn}_{2}(3)_{2}(\mathrm{Et})_{2}$ achieved $100 \%$ conversion to Me-LA within $8 \mathrm{~h}$ at $80^{\circ} \mathrm{C}$. Overall, mass transfer limitations due to polymer particle size and stirring speed were considered to be negligible based on previously reported work by McKeown et $a l .{ }^{41}$ on an analogous $\mathrm{Zn}$ (II)-imino monophenolate system.

\section{Degradation kinetics}

Both $\mathrm{Zn}(2)_{2}$ and $\mathrm{Zn}(3)_{3}$ were chosen for further analysis owing to their high degradation activity, stability and potential scalability. To ensure sufficiently short reaction times, degradation reactions were repeated under identical conditions at $80{ }^{\circ} \mathrm{C}$ (Table 5). Reaction progress was monitored hourly by taking aliquots for ${ }^{1} \mathrm{H}$ NMR $\left(\mathrm{CDCl}_{3}\right)$ analysis of the methine region (Fig. 4). $\mathrm{Zn}(2-3)_{2}$ achieved comparable yields of Me-LA after $8 \mathrm{~h}$, although $100 \%$ conversion to Me-LA was not achieved as pre-
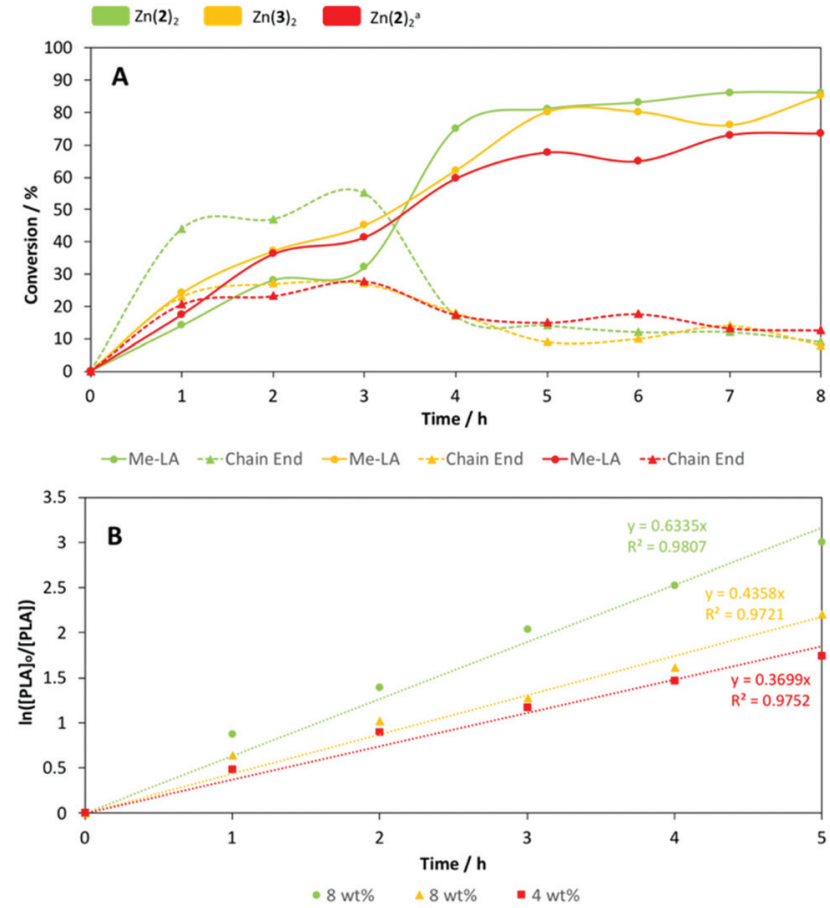

Fig. 4 (A) Vegware PLA cup degradation plot of conversion vs. time with $\mathrm{Zn}(2-3)_{2}$ at $8 \mathrm{wt} \%$ in THF at $80{ }^{\circ} \mathrm{C}$. ${ }^{\mathrm{a}}\left[\mathrm{Zn}(2)_{2}\right]=4 \mathrm{wt} \%$. (B) Pseudofirst-order logarithmic plots for the degradation of Vegware PLA cup with $\mathrm{Zn}(2-3)_{2}$ in $\mathrm{THF}$ at $80^{\circ} \mathrm{C}$. Line of best fit constrained to pass through the origin. 
Table 6 PLA cup degradation with $\mathrm{Zn}(2-3)_{2}$ in $\mathrm{THF}$ at $80^{\circ} \mathrm{C}^{\mathrm{a}, \mathrm{b}, \mathrm{c}}$

\begin{tabular}{lll}
\hline Init. & $Y_{\text {Me-LA }}{ }^{b} / \%$ & $k_{\text {app }} / \mathrm{h}^{-1}$ \\
\hline $\mathrm{Zn}(2)_{2}$ & 87 & $0.63 \pm 0.051$ \\
$\mathrm{Zn}(3)_{2}{ }{ }_{\mathrm{Zn}(2)_{2}}$ & 82 & $0.44 \pm 0.029$ \\
& 78 & $0.37 \pm 0.021$
\end{tabular}

${ }^{a}$ Reaction conditions: $0.25 \mathrm{~g}$ of PLA, $\mathrm{V}_{\mathrm{THF}}: \mathrm{V}_{\mathrm{MeOH}}=4: 1,\left[\mathrm{Zn}(2-3)_{2}\right]=$ $8 \mathrm{wt} \%$ cat. loading, $n_{\mathrm{MeOH}}: n_{\text {ester }}=7: 1 .{ }^{b}$ Maximum Me-LA conversion $\left(Y_{\text {Me-LA }}\right)$ determined via ${ }^{1} \mathrm{H}$ NMR $\left(\mathrm{CDCl}_{3}\right)$ analysis after $8 \mathrm{~h}$ upon solvent (THF) removal. ${ }^{c}$ Error associated with $k_{\text {app }}$ using linear regression. ${ }^{d}\left[\mathrm{Zn}(2)_{2}\right]=4 \mathrm{wt} \%$ cat. loading.

viously noted (Table 5). PLA degradation using $\mathrm{Zn}(2)_{2}$ was also tested at $4 \mathrm{wt} \%$. Interestingly, at a lower catalyst loading, a higher Me-LA conversion was achieved within $3 \mathrm{~h}$ compared to $8 \mathrm{wt} \%$, suggesting preferential transesterification of oligomer compared to polymer. However, the general degradation profile was retained, albeit with a less severe rapid conversion event, likely due to a shift in transesterification selectivity. As expected, a lower overall Me-LA conversion (78\%) was observed compared to $\mathrm{Zn}(2)_{2}$ at $8 \mathrm{wt} \%$. In all instances, fluctuations in Me-LA and oligomer yield ( $Y_{\mathrm{Me}-\mathrm{LA}}$ and $Y_{\mathrm{CE}}$ respectively) can likely be attributed to an equilibrium process. ${ }^{70}$ In accordance to kinetic work by Mckeown et al., ${ }^{41}$ PLA consumption was presumed to adopt pseudo-first-order kinetics (Fig. 2b). Thus, the gradient of the logarithmic plot is equivalent to the apparent rate constant, $k_{\text {app }}$ (Table 6). $\mathrm{Zn}(2-3)_{2}$ exhibited $k_{\text {app }}$ values of $0.63 \pm 0.051$ and 0.44 $\pm 0.029 \mathrm{~h}^{-1}$ respectively at $8 \mathrm{wt} \%$, indicating reduced sterics and electronics imparts a statistically significant reduction in activity. For $\mathrm{Zn}(2)_{2}$, a shift to $4 \mathrm{wt} \%$ coincided with a statistically significant reduction in $k_{\text {app }}\left(0.37 \pm 0.021 \mathrm{~h}^{-1}\right)$ as expected.

\section{Conclusion}

A series of novel mono- and dimeric $\mathrm{Zn}$ (II)-Schiff-base complexes were successfully synthesised and fully characterised. Their application in the ROP of rac-LA to produce biocompatible atactic PLA was demonstrated in both solution and under industrially preferred melt conditions, albeit with generally poor $M_{\mathrm{n}}$ control and broad dispersities $(\nexists)$. Additionally, their capacity to facilitate PLA degradation into Me-LA under mild conditions was shown. $\mathrm{Zn}(2)_{2}$ and $\mathrm{Zn}(3)_{2}$ emerged as the outstanding candidates, with both achieving $100 \%$ conversion to Me-LA within $8 \mathrm{~h}$ at $80^{\circ} \mathrm{C}$ in THF. Further degradation kinetic analysis revealed $\mathrm{Zn}(2-3)_{2}$ to possess $k_{\text {app }}$ values of $0.63 \pm 0.051$ and $0.44 \pm 0.029 \mathrm{~h}^{-1}$ respectively at $8 \mathrm{wt} \%$, indicating steric and electronic effects have a statistically significant impact on degradation activity. A statistically significant reduction in $k_{\text {app }}$ was observed for $\mathrm{Zn}(2)_{2}$ between 8 and $4 \mathrm{wt} \%$.

\section{Experimental}

An exemplar synthesis is provided below, see ESI $\dagger$ for full details.

\section{Ligand}

1H: To a solution of 3,5-di-tert-butyl-2-hydroxybenzaldehyde (4.68 g. $20 \mathrm{mmol}$ ) dissolved in $\mathrm{MeOH}$ (50 mL), aniline (1.86 g, $1.82 \mathrm{~mL}, 20 \mathrm{mmol}$ ) was added with stirring. The reaction mixture was then left to stir at RT for $18 \mathrm{~h}$, affording a yellow solid product. The product was then separated by filtration, washed with $\mathrm{MeOH}(5 \times 5 \mathrm{~mL})$ and dried in vacuo. Yield $=4.74 \mathrm{~g}, 77 \%$.

\section{Zn(II)-Complex}

$\mathrm{Zn}(\mathbf{1})_{2}$ : To a solution of $\mathbf{1 H}(0.62 \mathrm{~g}, 2 \mathrm{mmol})$ dissolved in anhydrous toluene $(10 \mathrm{~mL}), \mathrm{ZnEt}_{2}$ (1 $\mathrm{M}$ in hexane, $1 \mathrm{mmol}$ ) was added dropwise with stirring. After complete addition, the solution was stirred at RT for 15 minutes before being left to stand for $1 \mathrm{~h}$. The solvent was then removed via cannula filtration and the desired $\mathrm{Zn}$ (II) complex was recrystallised from hexane as yellow crystals. Yield $=0.50 \mathrm{~g}, 73 \%$.

\section{Polymerisation}

Polymerisations were conducted in a Youngs ampoule under argon. $r a c$-LA was recrystallised once from toluene prior to use. All melt polymerisations were performed in the absence of solvent. The reaction commenced on melting of the monomer and deemed finished once a polymer melt of sufficient viscosity stopped the stirrer bar. The reaction was then quenched in air and the product dissolved in DCM $(20 \mathrm{~mL})$ with stirring. The solvent was then removed in vacuo and a crude ${ }^{1} \mathrm{H}$ NMR spectrum of the polymer was obtained. The polymer was then washed with copious amounts of $\mathrm{MeOH}(100 \mathrm{~mL})$ to remove initiator and any unreacted monomer, dried in vacuo and retained for materials characterisation. Solution polymerisations were conducted in anhydrous toluene $(10 \mathrm{~mL})$ using the purification method described for the melt.

\section{Degradation}

All reactions were performed in a Youngs ampoule under argon. The flask was loaded with $\mathrm{Zn}$ (II) catalyst (8 wt\% $1 \mathrm{~mol} \%$ relative to PLA ester linkages, $0.02 \mathrm{~g}$ ) in a Glovebox to which PLA (0.25 g, Vegware ${ }^{\mathrm{TM}}$, PLA cup, $M_{\mathrm{n}}=45510 \mathrm{~g} \mathrm{~mol}^{-1}$ ) was added under a flow of argon. The polymer was then dissolved in THF ( $4 \mathrm{~mL})$, with heating and stirring assisting dissolution. The flask was then submerged in a preheated oil bath $\left(50\right.$ or $\left.80^{\circ} \mathrm{C}\right)$ to which $\mathrm{MeOH}(1 \mathrm{~mL})$ was added. Aliquots were taken for ${ }^{1} \mathrm{H} \mathrm{NMR}\left(\mathrm{CDCl}_{3}\right)$ analysis of the methine region. After the reaction, the solvent was removed in vacuo and the residual methyl lactate (Me-La) was analysed further.

\section{Conflicts of interest}

The authors declare no conflict of interest.

\section{Acknowledgements}

We wish to thank the EPSRC for funding and the University of Bath and $\mathrm{MC}^{2}$ for use of their analysis facilities. We would like 
to thank the EPSRC for funding (EP/L016354/1) for a PhD studentship to JP and (EP/P016405/1) for PM.

\section{References}

1 European Bioplastics, Facts and Fig. 2016, http://docs.europeanbioplastics.org/2016/publications/EUBP_Facts_and_ Figures_2017.pdf, (Accessed: 30th October 2018).

2 R. C. Thompson, C. J. Moore, F. S. vom Saal and S. H. Swan, Philos. Trans. R. Soc., B, 2009, 364, 2153-2166.

3 Y. Zhu, C. Romain and C. K. Williams, Nature, 2016, 540, 354-362.

4 Ellen MacArthur Foundation, The New Plastics Economy: Rethinking the future of plastics, 2016, https://www.ellenmacarthurfoundation.org/publications/the-new-plastics-economyrethinking-the-future-of-plastics, (Accessed: 7th January 2019).

5 M. Rabnawaz, I. Wyman, R. Auras and S. Cheng, Green Chem., 2017, 19, 4737-4753.

6 R. Geyer, J. R. Jambeck and K. L. Law, Sci. Adv., 2017, 3, 1-5.

7 Ellen MacArthur Foundation, The New Plastics Economy: Catalysing Action, 2016, https://www.ellenmacarthurfoundation.org/assets/downloads/New-Plastics-Economy_CatalysingAction_13-1-17.pdf, (Accessed: 9th January 2019).

8 E. T. H. Vink, K. R. Rábago, D. A. Glassner, B. Springs, R. P. O'Connor, J. Kolstad and P. R. Gruber, Macromol. Biosci., 2004, 4, 551-564.

9 E. T. H. Vink, D. A. Glassner, J. Kolstad, R. J. Wooley and R. P. O'Connor, Biotechnology, 2007, 3, 58-81.

10 M. Dusselier, P. V. Wouwe, A. Dewaele, P. A. Jacobs and B. F. Sels, Science, 2015, 349, 78-80.

11 R. De Clercq, M. Dusselier, C. Poleunis, D. P. Debecker, L. Giebeler, S. Oswald, E. Makshina and B. F. Sels, ACS Catal., 2018, 8, 8130-8139.

12 T. P. Haider, C. Völker, J. Kramm, K. Landfester and F. R. Wurm, Angew. Chem., Int. Ed., 2019, 58, 50-62.

13 J. Hopewell, R. Dvorak and E. Kosior, Philos. Trans. R. Soc., $B, 2009,364,2115-2126$.

14 H. Tsuji, H. Daimon and K. Fujie, Biomacromolecules, 2003, 4, 835-840.

15 Y. Aoyagi, K. Yamashita and Y. Doi, Polym. Degrad. Stab., 2002, 76, 53-59.

16 Y. Tokiwa, B. P. Calabia, C. U. Ugwu and S. Aiba, Int. J. Mol. Sci., 2009, 10, 3722-3742.

17 P. Coszach, J.-C. Bogaert and J. Willocq, US Pat, 8431683B2, 2013.

18 H. Tsuji, T. Saeki, T. Tsukegi, H. Daimon and K. Fujie, Polym. Degrad. Stab., 2008, 93, 1956-1963.

19 V. Piemonte and F. Gironi, J. Polym. Environ., 2013, 21, 313318.

20 C. F. Van Nostrum, T. F. J. Veldhuis, G. W. Bos and W. E. Hennink, Polymer, 2004, 45, 6779-6787.

21 F. Codari, S. Lazzari, M. Soos, G. Storti, M. Morbidelli and D. Moscatelli, Polym. Degrad. Stab., 2012, 97, 2460-2466.
22 S. Lazzari, F. Codari, G. Storti, M. Morbidelli and D. Moscatelli, Polym. Degrad. Stab., 2014, 110, 80-90.

23 K. Odelius, A. Höglund, S. Kumar, M. Hakkarainen, A. K. Ghosh, N. Bhatnagar and A. C. Albertsson, Biomacromolecules, 2011, 12, 1250-1258.

24 C. T. Bowmer, R. N. Hooftman, A. O. Hanstveit, P. W. M. Venderbosch and N. van der Hoeven, Chemosphere, 1998, 37, 1317-1333.

25 C. S. M. Pereira, V. M. T. M. Silva and A. E. Rodrigues, Green Chem., 2011, 13, 2658-2671.

26 J. J. Bozell and G. R. Petersen, Green Chem., 2010, 12, 539554.

27 Y. Fan, C. Zhou and X. Zhu, Catal. Rev.: Sci. Eng., 2009, 51, 293-324.

28 J. Payne, P. McKeown and M. D. Jones, Polym. Degrad. Stab., 2019, 165, 170-181.

29 M. Dusselier, P. V. Wouwe, A. Dewaele, E. Makshina and B. F. Sels, Energy Environ. Sci., 2013, 6, 1415-1442.

30 L. D. Brake, US Pat, 5264617, 1993.

31 X. Song, X. Zhang, H. Wang, F. Liu, S. Yu and S. Liu, Polym. Degrad. Stab., 2013, 98, 2760-2764.

32 X. Song, Z. Bian, Y. Hui, H. Wang, F. Liu and S. Yu, Polym. Degrad. Stab., 2019, 168, 108937-108944.

33 X. Song, H. Wang, X. Zheng, F. Liu and S. Yu, J. Appl. Polym. Sci., 2014, 131, 40817-40823.

34 F. Nederberg, E. F. Connor, T. Glausser and J. L. Hedrick, Chem. Commun., 2001, 2066-2067.

35 F. A. Leibfarth, N. Moreno, A. P. Hawker and J. D. Shand, J. Polym. Sci., Part A: Polym. Chem., 2012, 50, 48144822.

36 L. Monsigny, J.-C. Berthet and T. Cantat, ACS Sustainable Chem. Eng., 2018, 6, 10481-10488.

37 S. Westhues, J. Idel and J. Klankermayer, Sci. Adv., 2018, 4, 1-8.

38 E. M. Krall, T. W. Klein, R. J. Andersen, A. J. Nett, R. W. Glasgow, D. S. Reader, B. C. Dauphinais, S. P. McIlrath, A. A. Fischer, M. J. Carney, et al., Chem. Commun., 2014, 50, 4884-4887.

39 E. L. Whitelaw, M. G. Davidson and M. D. Jones, Chem. Commun., 2011, 47, 10004-10006.

40 C. Fliedel, D. Vila-Viçosa, M. J. Calhorda, S. Dagorne and T. Avilés, ChemCatChem, 2014, 6, 1357-1367.

41 L. A. Román-Ramírez, P. Mckeown, M. D. Jones and J. Wood, ACS Catal., 2019, 9, 409-416.

42 P. McKeown, L. A. Román-Ramírez, S. Bates, J. Wood and M. D. Jones, ChemSusChem, 2019, 12, 5233-5238.

43 R. Petrus, D. Bykowski and P. Sobota, ACS Catal., 2016, 6, 5222-5235.

44 H. Liu, X. Song, F. Liu, S. Liu and S. Yu, J. Polym. Res., 2015, 22, 135-141.

45 P. McKeown, S. N. McCormick, M. F. Mahon and M. D. Jones, Polym. Chem., 2018, 9, 5339-5347.

46 M. Fuchs, S. Schmitz, P. M. Schäfer, T. Secker, A. Metz, A. N. Ksiazkiewicz, A. Pich, P. Kögerler, K. Y. Monakhov and S. Herres-Pawlis, Eur. Polym. J., 2020, 122, 109302109308. 
47 P. M. Schäfer, M. Fuchs, A. Ohligschläger, R. Rittinghaus, P. McKeown, E. Akin, M. Schmidt, A. Hoffmann, M. A. Liauw, M. D. Jones and S. Herres-Pawlis, ChemSusChem, 2017, 10, 3547-3556.

48 J. Börner, I. Dos Santos Vieira, A. Pawlis, A. Döring, D. Kuckling and S. Herres-Pawlis, Chem. - Eur. J., 2011, 17, 4507-4512.

49 J. Börner, U. Florke, K. Huber, A. Döring, D. Kuckling and S. Herres-Pawlis, Chem. - Eur. J., 2009, 15, 2362-2376.

50 H.-Y. Chen, H.-Y. Tang and C.-C. Lin, Macromolecules, 2006, 39, 3745-3752.

51 H.-L. Chen, H.-J. Chuang, B.-H. Huang and C.-C. Lin, Inorg. Chem. Commun., 2013, 35, 247-251.

52 W.-C. Hung, Y. Huang and C.-C. Lin, J. Polym. Sci., Part A: Polym. Chem., 2008, 46, 6466-6476.

53 D. Jędrzkiewicz, G. Adamus, M. Kwiecień, Ł. John and J. Ejfler, Inorg. Chem., 2017, 56, 1349-1365.

54 M. Cheng, A. B. Attygalle, E. B. Lobkovsky and G. W. Coates, J. Am. Chem. Soc., 1999, 121, 11583-11584.

55 M. H. Chisholm, J. C. Huffman and K. Phomphrai, J. Chem. Soc., Dalton Trans., 2001, 222-224.

56 M. H. Chisholm, J. Gallucci and K. Phomphrai, Inorg. Chem., 2002, 41, 2785-2794.

57 M. H. Chisholm and K. Phomphrai, Inorg. Chim. Acta, 2003, 350, 121-125.

58 B. M. Chamberlain, M. Cheng, D. R. Moore, T. M. Ovitt, E. B. Lobkovsky and G. W. Coates, J. Am. Chem. Soc., 2001, 123, 3229-3238.
59 C. Kan, J. Hu, Y. Huang, H. Wang and H. Ma, Macromolecules, 2017, 50, 7911-7919.

60 S. Abbina and G. Du, ACS Macro Lett., 2014, 3, 689692.

61 D. E. Stasiw, A. M. Luke, T. Rosen, A. B. League, M. Mandal, B. D. Neisen, C. J. Cramer, M. Kol and W. B. Tolman, Inorg. Chem., 2017, 56, 14366-14372.

62 A. Thevenon, C. Romain, M. S. Bennington, A. J. P. White, H. J. Davidson, S. Brooker and C. K. Williams, Angew. Chem., Int. Ed., 2016, 55, 8680-8685.

63 C. K. Williams, L. E. Breyfogle, S. K. Choi, W. Nam, V. G. Young, M. A. Hillmyer and W. B. A. Tolman, J. Am. Chem. Soc., 2003, 125, 11350-11359.

64 P. P. Upare, Y. K. Hwang, J.-S. Chang and D. W. Hwang, Ind. Eng. Chem. Res., 2012, 51, 4837-4842.

65 A. C. Sanchéz and S. R. Collinson, Eur. Polym. J., 2011, 47, 1970-1976.

66 C. Alberti, N. Damps, R. R. R. Meißner, M. Hofmann, D. Rijono and S. Enthaler, Adv. Sustainable Syst., 2020, 4, 1900081.

67 C. Alberti, N. Damps, R. R. R. Meißner and S. Enthaler, ChemistrySelect, 2019, 4, 6845-6848.

68 A. Plichta, P. Lisowska, A. Kundys, A. Zychewicz, M. Dębowski and F. Florjańczyk, Polym. Degrad. Stab., 2014, 108, 288-296.

69 K. Hirao and H. Ohara, Polym. Rev., 2011, 51, 1-22.

70 D. Bykowski, A. Grala and P. Sobota, Tetrahedron Lett., 2014, 55, 5286-5289. 